\title{
Aplicação de Resinas Sulfônicas como Catalisadores em Reações de Transesterificação de Óleos Vegetais
}

\author{
Simone M. de Rezende, Bluma G. Soares \\ Instituto de Macromoléculas Profa Eloisa Mano, UFRJ \\ Fernanda M. B.Coutinho \\ Instituto de Química, UERJ \\ Instituto de Macromoléculas Profa Eloisa Mano, UFRJ
}

\author{
Simone C. M. dos Reis, Marcelli G. Reid, Elizabeth R. Lachter, Regina S. V. Nascimento \\ Instituto de Química, UFRJ
}

\begin{abstract}
Resumo: Diferentes suportes poliméricos à base de estireno (S) e divinilbenzeno (DVB) foram sintetizados e suas morfologias caracterizadas por microscopia óptica e eletrônica de varredura. Foram preparados e caracterizados catalisadores sulfônicos a partir desses suportes e suas atividades catalíticas foram avaliadas na transesterificação de óleo vegetal com metanol. Os resultados obtidos com esses catalisadores foram comparados com os produzidos com uma resina sulfônica comercial. Verificou-se que os catalisadores sintetizados neste trabalho apresentaram desempenhos próximos ao da resina comercial.
\end{abstract}

Palavras-chave: Resinas sulfônicas, síntese, caracterização, catálise heterogênea, transesterificação de óleo vegetal.

\section{Evaluation of Sulfonic Resins as Catalysts in Transesterification of Vegetable Oils}

\begin{abstract}
Different polymer supports based on styrene (S) and divinylbenzene (DVB) were synthesized and their morphology was characterized by optical and scanning electron microscopy. Sulfonic catalysts were prepared from these supports, characterized and their activities were evaluated in vegetal oil transesterification with methanol and compared with the performance of a commercial sulfonic resin. The synthesized catalysts showed results close to the commercial resin.
\end{abstract}

Keywords: Sulfonic resins, synthesis, characterization, heterogeneous catalysis, transesterification.

\section{Introdução}

As resinas sulfônicas à base de estireno-divinilbenzeno são os catalisadores poliméricos mais utilizados em laboratório e na indústria química. Essas resinas são normalmente preparadas em duas etapas. A primeira etapa consiste na síntese do copolímero de estireno-divinilbenzeno por meio de polimerização em suspensão. A estrutura porosa dos copolímeros é produzida com adição de diluentes inertes à mistura monomérica, que ao serem removidos após o término da polimerização liberam os poros. As características morfológicas dessas resinas (volume de poros, distribuição de tamanhos de poro e área específica) dependem do tipo e concentração dos diluentes, bem como do grau de ligações cruzadas. Conseqüentemente, a morfologia desses materiais pode variar desde uma estrutura gel até macroporosa. A atividade do catalisador polimérico é influenciada pelas características da resina e pelo teor de grupos sulfônicos incorporados em sua estrutura. Nosso grupo de pesquisa tem investido esforços na síntese e ava- liação desses catalisadores poliméricos em reações de interesse industrial como a esterificação de ácidos carboxílicos e a alquilação de compostos aromáticos ${ }^{[1,2]}$.

Recentemente, devido ao aumento dos preços do óleo cru, dos recursos limitados de óleo fóssil e, principalmente, devido a razões ambientais, os óleos vegetais e gorduras animais têm sido foco de interesse para a produção de biodiesel, combustível caracterizado pelo seu mais baixo impacto ambiental ${ }^{[3,4]}$. Entretanto, o uso direto de óleo vegetal como combustível é problemático devido a sua elevada viscosidade $(33,4 \mathrm{cP})$ e baixa volatilidade. Diferentes caminhos têm sido considerados para reduzir a alta viscosidade dos óleos vegetais. A transesterificação mostrou ser uma possibilidade de escolha ${ }^{[5]}$.

$\mathrm{Na}$ transesterificação (Figura 1) de óleos vegetais ou gorduras, um triglicerídeo reage com um álcool, em presença de ácido ou base forte, produzindo uma mistura de ésteres de ácidos graxos e glicerol ${ }^{[3]}$.

Esse processo é catalisado por ácidos de Brönsted, preferencialmente por ácido sulfúrico, ou por bases tais como

Autor para correspondência: Fernanda M. B. Coutinho, Instituto de Macromoléculas Professora Eloisa Mano, UFRJ, Caixa Postal 68525, CEP: 21945-970, Rio de Janeiro, RJ.E-mail: fern@uerj.br 


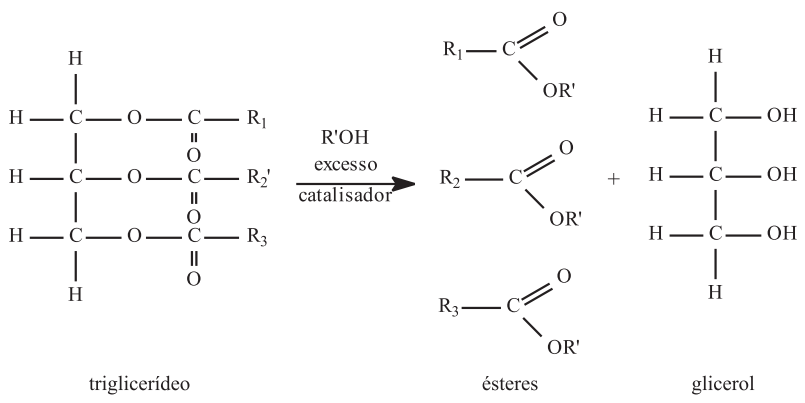

Figura 1. Representação esquemática da reação de transesterificação ${ }^{[3]}$

hidróxido de sódio ou hidróxido de potássio. Quando os triglicerídeos apresentam baixos teores de ácidos graxos livres, a catálise básica é normalmente empregada na transesterificação. Entretanto, se os teores de ácidos livres são altos, a catálise ácida é recomendada ${ }^{[3]}$. A utilização de catalisadores sólidos em processos catalisados por ácidos tem recebido atenção especial nos últimos anos devido à facilidade de separação do produto do meio reacional, e ao fato de serem menos corrosivos e menos poluentes ${ }^{[6]}$. As resinas sulfônicas (trocadoras de cátions), principalmente as macroporosas, são catalisadores versáteis e podem ser utilizadas em substituição ao seu análogo homogêneo $\left(\mathrm{H}_{2} \mathrm{SO}_{4} \mathrm{ou}\right.$ ácido $p$-tolueno-sulfônico) em diversas reações orgânicas. Geralmente, a pureza do produto e o rendimento são superiores e as resinas apresentam ainda a vantagem de poderem ser empregadas tanto em meio aquoso como não-aquoso ${ }^{[7]}$. A Figura 2 mostra a representação esquemática da reação de transesterificação utilizando como catalisador uma resina sulfônica ${ }^{[8]}$.

Assim, este trabalho teve como objetivo a síntese, a caracterização e a avaliação de resinas sulfônicas, em reações de transesterificação de óleos vegetais, no caso o óleo de coco de babaçu, para o desenvolvimento de um processo alternativo e ecologicamente correto para a produção de biodiesel. Foram utilizadas, como catalisadores, várias resinas sulfônicas e os resultados comparados com o obtido com uma resina comercial macroporosa (resina Amberliyst 15).

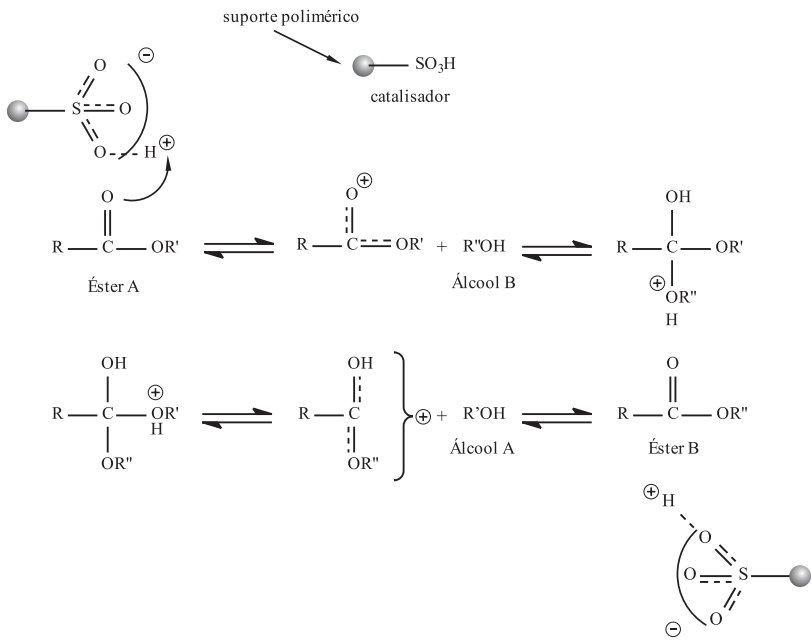

Figura 2. Representação esquemática da reação de transesterificação catalisada por uma resina sulfônica ${ }^{[8]}$

\section{Materiais e Métodos}

\section{Síntese dos copolímeros de estireno-divinilbenzeno (S-DVB)}

Os copolímeros de S-DVB foram preparados por meio de polimerização em suspensão aquosa em balão de três bocas de fundo redondo de $1000 \mathrm{~mL}$ de capacidade equipado com agitador mecânico e condensador de refluxo. Inicialmente, foi adicionada a fase aquosa que continha hidroxietilcelulose $(0,2 \% \mathrm{~m} / \mathrm{v}$ em relação ao volume de água) como estabilizador da suspensão e cloreto de sódio $(\mathrm{NaCl} 0,5 \% \mathrm{~m} / \mathrm{v}$ em relação ao volume de água) para diminuir a solubilidade dos monômeros na água. Em seguida, foi adicionada a fase orgânica constituída pelo iniciador, peróxido de benzoíla (BPO), em concentração igual a $1 \%$ em relação a soma do número de moles dos monômeros, estireno (S) e divinilbenzeno (DVB), e a mistura de diluentes (tolueno e n-heptano). A fase orgânica foi então dispersa na fase aquosa durante 10 minutos e em seguida, a mistura reacional sob agitação mecânica foi aquecida a $90{ }^{\circ} \mathrm{C}$ em banho termostatizado. A razão fase aquosa/fase orgânica e a velocidade de agitação foram mantidas constantes em 4/1 (v/v) e $500 \mathrm{rpm}$ respectivamente em todas as reações. Após 30 horas de reação, as pérolas de copolímero S-DVB resultantes foram separadas por filtração a pressão reduzida (trompa d'água).

As pérolas foram purificadas por lavagens com água e etanol. O objetivo da lavagem com água foi a eliminação do estabilizador da suspensão e a lavagem com etanol teve a finalidade de eliminar os monômeros residuais e diluentes dos poros do copolímero. As pérolas de copolímero foram, então, peneiradas em peneirador hidráulico utilizando peneiras de 25,45 , $80,100,140$ e 200 mesh. As pérolas na faixa granulométrica 45-80 mesh $(0,2$ a $0,35 \mathrm{~mm})$ foram lavadas com metanol, para produzir estruturas com poros livres de impurezas, e secas em estufa, a aproximadamente $60^{\circ} \mathrm{C}$, por 48 horas. Esta foi a faixa granulométrica utilizada para os testes de caracterização e, posteriormente, para a sulfonação, para a produção dos catalisadores sulfônicos. Esta foi a faixa escolhida, pois foi produzida em maior rendimento (em torno de $70 \%$ ).

\section{Sulfonação dos copolímeros S-DVB}

Na reação de sulfonação foi usada uma velocidade de agitação suficiente apenas para a homogeneização do meio, de modo a evitar a quebra das pérolas durante a sulfonação.

As reações de sulfonação foram realizadas em presença de um solvente com capacidade de inchar o copolímero, 1,2dicloroetano (DCE). A relação solvente/copolímero foi mantida constante em $10 \mathrm{~mL}$ de solvente para $1 \mathrm{~g}$ de copolímero. Inicialmente, o copolímero foi deixado em presença do solvente durante 24 horas. Em seguida, foi adicionado um excesso de ácido sulfúrico concentrado, na relação $15 \mathrm{~mL}$ para $1 \mathrm{~g}$ de copolímero. A mistura reacional foi mantida, sob agitação branda, durante 1 hora a $90{ }^{\circ} \mathrm{C}$.

\section{Caracterização dos copolímeros S-DVB}

Os catalisadores sulfônicos foram caracterizados pelos métodos descritos a seguir: 
Densidade aparente - a densidade aparente foi determinada utilizando uma modificação do método ASTM D1895 $5^{[9]}$. Em proveta de $10 \mathrm{~mL}$ de capacidade, previamente pesada, foram adicionados, cuidadosamente para não sujar as paredes da proveta, em torno de 5 a $6 \mathrm{~mL}$ de amostra seca (copolímero ou catalisador) e determinado o peso da proveta com a amostra. Em seguida, o leito da amostra foi compactado e nivelado sob vibração (com o auxílio de um bastão de vidro revestido de borracha). Após a compactação do leito da amostra, o volume foi determinado. Finalmente, a densidade aparente $\left(d_{a p}\right)$ foi calculada por meio da expressão (1).

$$
\mathrm{d}_{\mathrm{ap}}=\frac{\text { massa da amostra }}{\text { volume da amostra }}
$$

A determinação da densidade aparente $\mathrm{d}_{\mathrm{ap}}$ é um método simples e eficiente para avaliar a variação de porosidade em copolímeros esféricos.

Área específica - determinada por meio dos dados de adsorção de nitrogênio em equipamento ASAP (Micromeritics, Mod. 2010 - ASAP) $)^{[10,11]}$.

Inchamento percentual em solventes - os valores de inchamento foram determinados em proveta de $10 \mathrm{~mL}$ de capacidade. Foram colocados na proveta cerca de $3 \mathrm{~mL}$ de copolímero sulfonado seco e o leito foi compactado e nivelado sob vibração (com o auxílio de um bastão de vidro revestido de borracha). No início da análise, foi realizada a leitura do volume inicial $\left(\mathrm{v}_{\mathrm{i}}\right)$. Em seguida, o solvente foi adicionado pelas paredes da proveta, sendo então, novamente submetida à vibração com a finalidade de compactar o leito da amostra e eliminar bolhas de ar. Após 24 horas, o volume de inchamento máximo $\left(\mathrm{v}_{\mathrm{f}}\right)$ foi obtido ${ }^{[12,13]}$. O inchamento dos catalisadores foi avaliado em água e em metanol. O inchamento percentual em água é um meio de avaliar a hidrofilicidade do catalisador. O inchamento percentual foi então calculado por meio da expressão (2).

$$
\mathrm{I}=\frac{\mathrm{v}_{\mathrm{f}}-\mathrm{v}_{\mathrm{i}}}{\mathrm{v}_{\mathrm{i}}} \times 100
$$

Avaliação do aspecto morfológico - o aspecto óptico dos catalisadores foi observado com o auxílio de microscópio óptico (Olympus, Mod. SZ10), equipado com câmera fotográfica.

Espectroscopia na região do infravermelho - os copolímeros e catalisadores foram caracterizados por espectroscopia na região do infravermelho (Perkin-Elmer 1720X FTIR). As amostras foram analisadas como pastilhas de $\mathrm{KBr}$ contendo aproximadamente $1 \% \mathrm{~m} / \mathrm{m}$ de amostra. Para cada espectro de FTIR, foram realizadas 50 aquisições (scans), com resolução de $4 \mathrm{~cm}^{-1}$, na faixa de freqüência de 400 a $4000 \mathrm{~cm}^{-1[14]}$.

Capacidade de troca catiônica dos catalisadores sulfônicos - o número de grupos capazes de trocar cátions foi determinado por conversão dos grupos sulfônicos do catalisador para a forma ácida $\left(\mathrm{H}^{+}\right)$por meio de tratamento com um excesso de ácido nítrico $\left(\mathrm{HNO}_{3}, 1 \mathrm{M}\right)$. Após o tratamento com ácido, o catalisador foi lavado com água deionizada para remover o excesso de ácido e em seguida neutralizado com um excesso conhecido de solução padrão de hidróxido de sódio, $0,1 \mathrm{M}$ $(\mathrm{NaOH})^{[15]}$. A capacidade de troca catiônica foi então calculada por meio da expressão (3).

$$
\text { Cap. troca }=\frac{\left(100 \mathrm{~mL} \times \mathrm{N}_{\mathrm{NaOH}}\right)-4\left(\mathrm{~mL}_{\mathrm{HCl}} \times \mathrm{N}_{\mathrm{HCl}}\right)}{\text { massa de amostra } \times \frac{\% \text { teor de sólidos }}{100}}
$$

onde:

Cap $=$ capacidade de troca catiônica, meq de grupos sulfônicos/g de catalisador na forma protonada $\mathrm{N}_{\mathrm{NaOH}}=$ normalidade da solução de $\mathrm{NaOH}$ utilizada; $\mathrm{mL}_{\mathrm{HCl}}=$ mililitros de $\mathrm{HCl}$ gastos na titulação;

$\mathrm{N}_{\mathrm{HCL}}=$ normalidade da solução de $\mathrm{HCl}$ utilizada na titulação

Reações de Transesterificação - as reações de transesterificação foram realizadas utilizando a relação molar metanol/óleo vegetal de 300/1 e $1 \mathrm{~g}$ de catalisador sulfônico. As reações foram conduzidas à temperatura de refluxo da mistura sob agitação magnética por 8 horas. Em seguida, adicionou-se água destilada $(30 \mathrm{~mL})$ e hexano $(15 \mathrm{~mL})$ cada uma. A mistura foi agitada, ocorrendo a separação em duas fases: uma aquosa e uma orgânica. A fase orgânica foi separada e a fase aquosa extraída com $15 \mathrm{~mL}$ de hexano (3 vezes). À fase orgânica foi adicionado o agente dessecante (sulfato de magnésio anidro - para secagem da fase orgânica). Após a separação do agente dessecante e evaporação do solvente, a mistura de ésteres foi submetida a análise por ressonância magnética nuclear do hidrogênio conforme descrito na literatura ${ }^{[16]}$.

Ressonância Magnética Nuclear de ${ }^{1} H$ - a ressonância magnética nuclear do hidrogênio $\left(\mathrm{RMN}^{1} \mathrm{H}\right)$ foi realizada em aparelho Brucker 200, com um campo magnético de 4,7 Tesla e freqüências de operação de $200 \mathrm{MHz}$ para o ${ }^{1} \mathrm{H}$. O solvente utilizado para análise da fase orgânica foi o clorofórmio deuterado. Através da análise dos espectros de $\mathrm{RMN}^{1} \mathrm{H}$ do óleo vegetal e das alíquotas da mistura reacional foi possível acompanhar o andamento da reação e calcular o teor em ésteres metílicos na reação. Os deslocamentos químicos referentes aos principais hidrogênios dos glicerídeos e dos ésteres metílicos estão resumidos na Figura 3.

Os sinais relevantes escolhidos para o cálculo de teor de ésteres metílicos na reação são aqueles referentes aos grupos metoxila dos ésteres, localizados em 3,7 ppm (singlete s) e aos dois grupos $\mathrm{CH}_{2}$ do glicerol esterificado (triglicerídeo) na faixa de 4,1 a 4,4 ppm (multiplete - m).
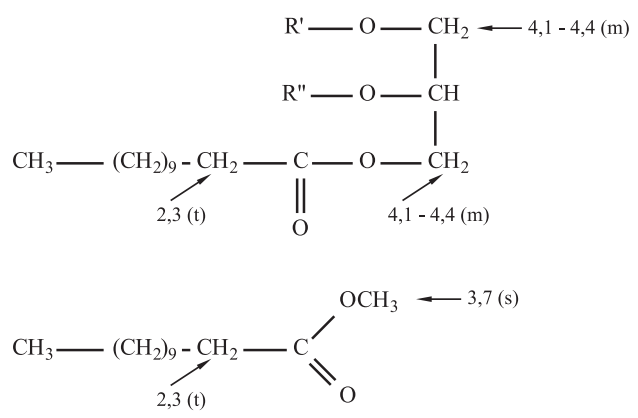

Figura 3. Principais deslocamentos químicos dos hidrogênios dos glicerídeos e dos ésteres metílicos 
$\mathrm{O}$ teor em éster para as reações de transesterificação (Y\%) foi obtido diretamente a partir das áreas dos sinais considerados relevantes, por meio da expressão (4).

$$
\mathrm{Y} \%=100\left[\frac{\left(\mathrm{A}_{1} / 3\right)}{\left(\mathrm{A}_{1} / 3\right)+\left(\mathrm{A}_{2} / 4\right)}\right]
$$

Onde $A_{1}$ e $A_{2}$ são as áreas da metoxila e do $\mathrm{CH}_{2}$ do glicerol esterificado (triglicerídeo) respectivamente.

\section{Resultados e Discussão}

\section{Influência das variáveis reacionais sobre as características dos catalisadores sulfônicos no estado seco}

A Tabela 1 mostra as características morfológicas, no estado seco, dos copolímeros sulfonados (catalisador sulfônico) obtidos a partir de copolímeros de S-DVB sintetizados com teores variados de DVB (10, 20, 40 e $60 \%$ ) e com 100 ou $150 \%$ de grau de diluição em relação ao volume da fase monomérica (volume total de monômeros).

Independente do grau de diluição, o aumento do teor de DVB, de $10 \%$ para $40 \%$, praticamente, não alterou os valores de densidade aparente, indicando que esses catalisadores não apresentam porosidade no estado seco, ou esta é muito baixa (caso dos catalisadores com $40 \%$ de DVB), confirmada pelos baixos valores de área específica $\left(7,3\right.$ e $\left.8 \mathrm{~m}^{2} / \mathrm{g}\right)$. Somente os catalisadores obtidos a partir de copolímeros com $60 \%$ de DVB apresentaram um decréscimo nos valores de densidade aparente, significando que esses catalisadores ficaram mais porosos. Esse aumento na porosidade pode ser confirmado pelos mais altos valores de área específica $\left(83 \mathrm{e} 19 \mathrm{~m}^{2} / \mathrm{g}\right)$.

Para os catalisadores obtidos a partir de copolímeros preparados com $40 \%$ de DVB e grau de diluição de $150 \%$, os valores de densidade aparente apresentaram um decréscimo (de 0,83 para 0,73 ), isto é, os catalisadores se tornaram mais porosos, à medida que o teor de n-heptano na mistura diluente aumentou de 50 para $70 \%$. O aumento da porosidade foi confirmado pelo aumento do valor de área específica (de 3 para $8 \mathrm{~m}^{2} / \mathrm{g}$ ) (Tabela 1).

Os valores da densidade aparente dos catalisadores obtidos com $100 \%$ de grau de diluição foram ligeiramente menores do que os obtidos com $150 \%$ de grau de diluição. Esse comportamento foi confirmado pelos maiores valores de área específi-
Tabela 1. Características morfológicas dos catalisadores sulfônicos obtidos a partir de suportes de S-DVB sintetizados com 100 e $150 \%$ de grau de diluição

\begin{tabular}{ccccc}
\hline Código & $\begin{array}{c}\text { Teor de DVB } \\
(\% \text { molar })\end{array}$ & $\begin{array}{c}\text { Razão tol/hep } \\
(\% \mathbf{v} / \mathbf{v})\end{array}$ & $\begin{array}{c}\mathbf{d}_{\text {ap }} \\
\left(\mathbf{c m}^{3} / \mathbf{g}\right)\end{array}$ & $\begin{array}{c}\mathbf{A} \\
\left(\mathbf{m}^{2} / \mathbf{g}\right)\end{array}$ \\
\hline A-15 & 40 & - & 0,56 & 53 \\
\hline CP-09 & 10 & 0,73 & $\mathrm{~nm}$ \\
CP-10B & 20 & $50 / 50$ & 0,75 & $\mathrm{~nm}$ \\
CP-11B & 40 & & 0,73 & 7 \\
CP-12 & 60 & 0,66 & 83 \\
\hline & $150 \%$ grau de diluição diluição & & \\
\hline CP-21 & 10 & & 0,82 & $\mathrm{~nm}$ \\
CP-22 & 20 & & 0,85 & $\mathrm{~nm}$ \\
CP-23 & 40 & $50 / 50$ & 0,83 & 3 \\
CP-24 & 60 & & 0,73 & 19 \\
\hline CP-19 & 40 & $30 / 70$ & 0,73 & 8 \\
\hline
\end{tabular}

A-15= resina comercial; $\mathrm{DVB}=$ divinilbenzeno; tol/hep= tolueno/ $\mathrm{n}$-heptano; $\mathrm{d}_{\mathrm{ap}}=$ densidade aparente; $\mathrm{A}=$ área específica; $\mathrm{nm}=$ não mensurável

ca, obtidos para os catalisadores produzidos com $100 \%$ de grau de diluição, mais porosos. Esse efeito pode ser atribuído ao fato de as cadeias do copolímero precursor, produzidas em um meio mais diluído, serem estruturas mais colapsadas no estado seco (em ausência de um diluente), e assim, mais densas.

A Figura 4 mostra o efeito gradual do aumento da porosidade com o aumento do teor de DVB para os catalisadores obtidos a partir de copolímeros produzidos com $100 \%$ de grau de diluição e composição volumétrica (50/50) da mistura diluente (tolueno/n-heptano). O aumento da porosidade é acompanhado pelo aumento da opacidade das pérolas.

Os suportes e os catalisadores foram caracterizados por espectroscopia na região do infravermelho. Nas Figuras 5 (a) e (b) são apresentados espectros para copolímeros e catalisadores preparados com $10 \%$ de DVB, tolueno/n-heptano $=50 / 50 \mathrm{e}$ graus de diluição de 100 e $150 \%$ respectivamente. Pode-se
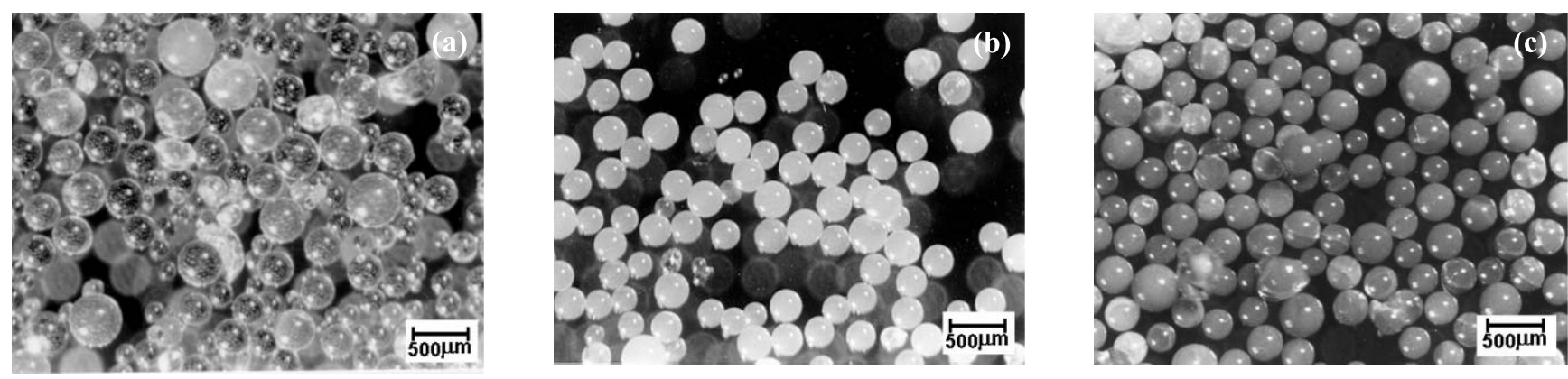

Figura 4: Micrografias de microscopia ótica dos catalisadores sulfônicos obtidos a partir de copolímeros com teores variados de DVB, composição da mistura diluente de 50/50 tolueno/n-heptano e grau de diluição de 100\%: (a) CP-09 com 10\% de DVB, (b) CP-11B com 40\% de DVB e (c) CP-12 com 60\% de DVB (aumento 20X). 

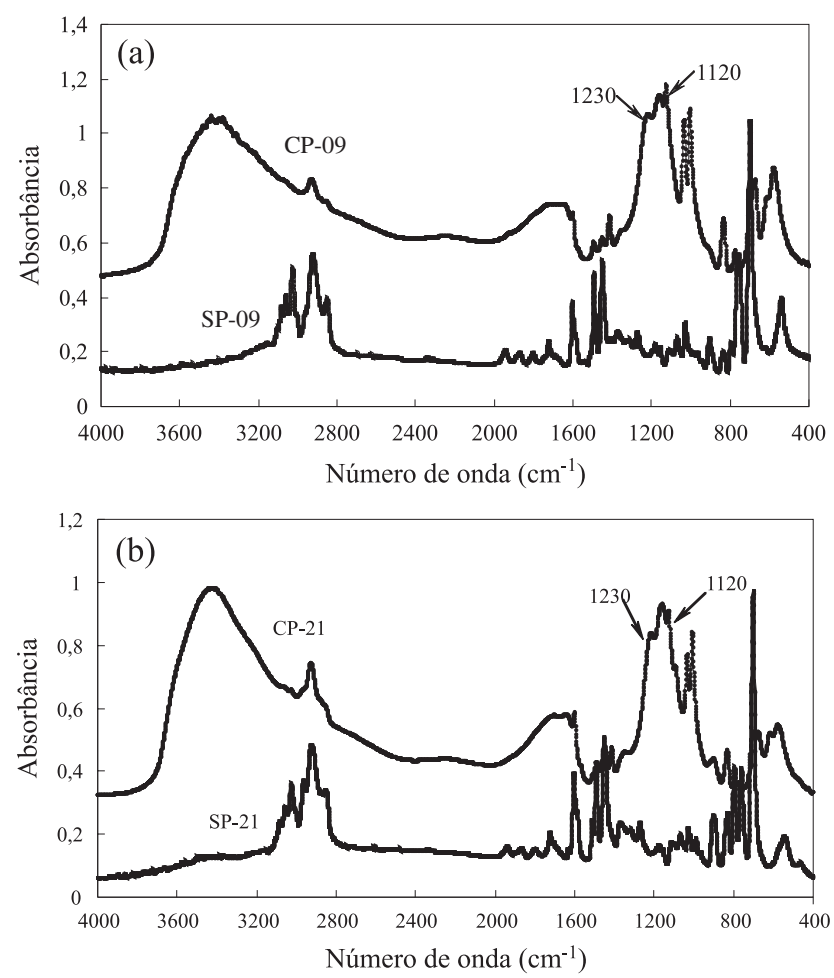

Figura 5. Espectros de FTIR dos suportes e dos catalisadores sintetizados com $10 \%$ DVB, tolueno/n-heptano= $50 / 50$ e diferentes graus de diluição: (a) SP-09 e CP-09 (100\% diluição) e (b) SP-21 e CP-21 (150\% diluição).

observar nos espectros dos catalisadores, uma banda na faixa de número de onda de 1120 a $1230 \mathrm{~cm}^{-1}$, característica do gru- po sulfonato. Ácidos sulfônicos, quando em sua forma anidra, absorvem em duas regiões estreitas de número de onda: 1342 $-1350 \mathrm{~cm}^{-1}$ e em $1150-1165 \mathrm{~cm}^{-1}$. Todavia, em ausência de tratamento especial de secagem das amostras e de manipulação em atmosfera anidra, os grupos sulfônicos se hidratam rapidamente formando sulfonatos de hidrônio, que absorvem na faixa de número de onda de $1120 \mathrm{~cm}^{-1}$ a $1230 \mathrm{~cm}^{-1[17]}$

\section{Influência das variáveis reacionais sobre as características dos catalisadores sulfônicos no estado inchado}

Os catalisadores foram preparados em presença de 1,2dicloroetano, um bom solvente para os copolímeros de SDVB, para que a reação de sulfonação ocorresse por toda a estrutura do suporte, tanto na superfície dos poros como no seu interior ${ }^{[18]}$.

As características dos catalisadores sulfônicos, no estado inchado, são apresentadas na Tabela 2. O inchamento percentual dos catalisadores foi realizado para avaliar a sua capacidade de inchar em água (meio no qual foi determinada a capacidade de troca catiônica) e em metanol (meio utilizado na reação de transesterificação). A presença de grupos sulfônicos na resina aumenta o seu caráter hidrofílico em relação ao copolímero S-DVB que, devido ao seu caráter apolar, não tem afinidade por solventes polares.

Para um mesmo grau de diluição (100 ou 150\%), o aumento do teor de DVB, na síntese dos copolímeros precursores, ocasionou um decréscimo nos valores de inchamento percentual, tanto em água como em metanol. Esse efeito pode ser atribuído ao fato de as estruturas formadas serem mais

Tabela 2. Capacidade de inchamento dos catalisadores sulfônicos obtidos a partir de suportes de S-DVB sintetizados com 100 e 150 \% de grau de diluição

\begin{tabular}{|c|c|c|c|c|c|c|}
\hline Código & $\begin{array}{c}\text { Teor de DVB } \\
\text { (\% molar) }\end{array}$ & $\begin{array}{c}\text { Razão tol/hep } \\
(\% \text { v/v })\end{array}$ & $\begin{array}{l}\mathbf{I}_{\mathrm{H}_{2} \mathrm{O}} \\
(\%)\end{array}$ & $\begin{array}{l}\text { Cap. troca } \\
\text { meq }_{\mathrm{so}_{3 \mathrm{H}}} / \mathrm{g}_{\mathrm{cat}}\end{array}$ & $\begin{array}{c}\mathbf{I}_{\mathrm{MeOH}} \\
(\%)\end{array}$ & $\begin{array}{l}\text { Trans. } \\
\text { (\% éster) }\end{array}$ \\
\hline A-15 & 40 & - & 13 & 5,5 & 13 & 80 \\
\hline \multicolumn{7}{|c|}{$100 \%$ grau de diluição } \\
\hline CP-09 & 10 & \multirow{4}{*}{$50 / 50$} & 280 & 5,7 & 266 & 67 \\
\hline CP-10B & 20 & & 126 & 4,8 & 137 & 54 \\
\hline CP-11B & 40 & & 86 & 4,4 & 85 & 72 \\
\hline CP-12 & 60 & & 67 & 3,7 & 60 & 66 \\
\hline
\end{tabular}

$150 \%$ grau de diluição

\begin{tabular}{|c|c|c|c|c|c|c|}
\hline CP-21 & 10 & \multirow{4}{*}{$50 / 50$} & 267 & 5,4 & 237 & 48 \\
\hline CP-22 & 20 & & 190 & 4,9 & 179 & 57 \\
\hline CP-23 & 40 & & 84 & 4,4 & 121 & 65 \\
\hline $\mathrm{CP}-24$ & 60 & & 26 & 3,8 & 46 & 66 \\
\hline CP-19 & 40 & $30 / 70$ & 117 & 4,3 & 132 & 62 \\
\hline
\end{tabular}

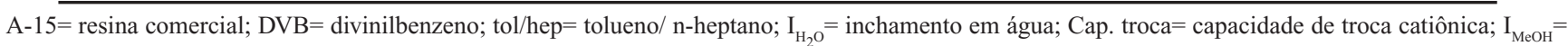
inchamento em metanol; Trans.= transesterificação 
rígidas em função do aumento do grau de ligações cruzadas. Isso provoca o aumento do emaranhamento das cadeias poliméricas, que por sua vez dificulta a penetração do solvente e, conseqüentemente, diminui o inchamento.

O inchamento percentual em metanol serve para avaliar a afinidade da resina por esse solvente. Assim, durante a transesterificação, se a resina apresenta uma alta capacidade de inchar em metanol, os sítios catalíticos $\left(-\mathrm{SO}_{3} \mathrm{H}\right)$ serão mais acessíveis à mistura reacional. $\mathrm{O}$ inchamento em metanol segue o mesmo perfil de comportamento que o inchamento em água. $\mathrm{O}$ inchamento em metanol diminui à medida que $\mathrm{o}$ teor de DVB aumenta, isto é, à medida que a estrutura polimérica se torna mais rígida.

Para os catalisadores obtidos a partir de copolímeros com $40 \%$ de DVB e grau de diluição de $150 \%$, o aumento do teor de mau-solvente (n-heptano) tornou o polímero mais poroso (maior área específica e mais baixa densidade) e consequentemente provocou um aumento na capacidade de inchamento em metanol.

A capacidade de troca catiônica determina o teor de grupos sulfônicos acessíveis em meio aquoso. A quantidade de íons retidos pelo catalisador polimérico depende da afinidade dos íons pelo grupo sulfônico e do grau de inchamento da estrutura polimérica. A capacidade de troca catiônica dos catalisadores é dada em meq $\mathrm{SO}_{3} \mathrm{~K} / \mathrm{g}_{\text {catalisador }}$.

De acordo com a Tabela 2, os valores de capacidade de troca catiônica diminuíram com o aumento do teor de DVB na síntese dos copolímeros precursores, independente do grau de diluição utilizado. Esses valores diminuíram devido à dificuldade de acesso aos grupos sulfônicos situados no interior da estrutura polimérica do tipo gel. O aumento do teor de DVB favoreceu a formação de estruturas mais reticuladas e assim mais rígidas, que dificultam o inchamento e, consequentemente, a troca iônica, provocando o decréscimo dos valores de capacidade (Figura 6).

\section{Avaliação dos catalisadores sulfônicos na transesterificação de óleo de babaçu com metanol}

A atividade dos catalisadores sulfônicos está associada ao teor de grupos ativos $\left(-\mathrm{SO}_{3} \mathrm{H}\right)$ e a sua acessibilidade. Assim, a atividade catalítica das resinas sulfonadas é função de sua morfologia, ou seja, quanto menor a rigidez das cadeias, mais

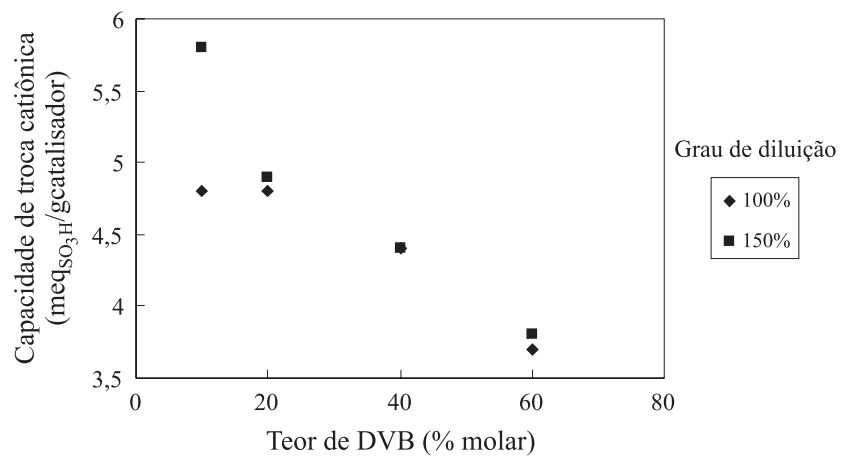

Figura 6. Capacidade de troca catiônica versus teor de DVB dos catalisadores obtidos a partir de copolímeros de S-DVB.
Tabela 3. Comparação dos teores de ésteres obtidos com o suporte S-DVB, a resina comercial e os catalisadores sulfônicos

\begin{tabular}{cccc}
\hline Código & $\begin{array}{c}\text { Teor de DVB } \\
(\% \text { molar })\end{array}$ & $\begin{array}{c}\text { Teor de éster } \\
(\boldsymbol{\%})\end{array}$ & $\begin{array}{c}\text { Capacidade } \\
\text { de troca } \\
\text { meq }_{\mathrm{s}_{3} \mathrm{H}} \mathrm{g}_{\mathrm{at}}\end{array}$ \\
\hline SP-09 & 10 & - & - \\
AMBERLYST-15 & 40 & 80 & 5,5 \\
\hline CP-09 & 10 & 67 & 5,7 \\
CP-21 & & 48 & 5,4 \\
\hline CP-10B & 20 & 54 & 4,8 \\
CP-22 & & 57 & 4,9 \\
\hline CP-11B & 40 & 72 & 4,4 \\
CP-19 & & 62 & 4,3 \\
CP-23 & & 65 & 4,4 \\
\hline CP-12 & 60 & 66 & 3,7 \\
CP-24 & & 66 & 3,8 \\
\hline
\end{tabular}

$\mathrm{DVB}=$ divinilbenzeno; o copolímero SP-09 não possui grupo sulfônico

fácil é o acesso aos grupos ativos e, consequentemente, mais alta é a atividade catalítica.

Primeiramente, foi conduzido um teste em branco em que se adicionou à mistura reacional (óleo e metanol) $1 \mathrm{~g}$ do copolímero S-DVB (SP-09, Tabela 3) e se submeteu essa mistura às mesmas condições reacionais (tempo e temperatura) utilizadas com os catalisadores sulfônicos. Ao final do tempo estipulado, não foi possível isolar o éster (Tabela 3).

Utilizando os catalisadores sulfônicos, obtidos a partir de copolímeros sintetizados com 100 ou $150 \%$ de grau de diluição, em reações de transesterificação do óleo de babaçu, verificou-se (Tabela 2) que os mais altos rendimentos de ésteres metílicos foram obtidos com os catalisadores mais porosos, ou seja aqueles com os mais altos teores de DVB. Os catalisadores que apresentaram os mais elevados inchamentos em metanol também mostraram atividade elevadas, embora com tendência para valores mãos baixos do que os apresentados pelos catalisadores mais porosos.

A Tabela 3 compara os rendimentos de ésteres metílicos obtidos com os catalisadores poliméricos sulfônicos preparados em nosso laboratório com os obtidos com a resina AMBERLYST 15. Essa resina comercial possui valor de capacidade de troca catiônica próximo ao obtido para os catalisadores poliméricos sulfônicos sintetizados neste trabalho. O mais alto rendimento de éster metílico encontrado com a resina comercial pode ser atribuído a sua mais alta porosidade, indicada pelo seu baixo valor de densidade aparente $\left(0,56 \mathrm{~cm}^{3} / \mathrm{g}\right)$ e pelos baixos valores de inchamento tanto em água (13\%) como em metanol (13\%).

\section{Conclusões}

Entre todos os catalisadores obtidos o mais poroso foi o sintetizado com $60 \%$ de DVB, 30/70 de toluenp/n-heptano e $100 \%$ de grau de diluição (CP-12); 
Por meio dos espectros de FTIR, copolímero e catalisador, pode-se observar que, os catalisadores realmente sofreram modificação química após a reação de sulfonação;

Os mais altos rendimentos de ésteres metílicos foram obtidos com os catalisadores mais porosos, ou seja, os que possuem os mais altos teores de DVB (40 e 60\%). Apesar de possuírem uma estrutura mais densamente reticulada que desfavorece o inchamento na mistura reacional essa maior porosidade (permanente) facilita o acesso da mistura aos grupos ativos do catalisador, independente do seu grau de inchamento;

O catalisador CP-09 apesar de ser menos poroso que os demais catalisadores, apresentou um alto rendimento de éster metílico, esse resultado pode ser atribuído ao seu mais alto grau de inchamento e sua maior capacidade de troca catiônica; A diferença encontrada entre os teores de ésteres metílicos produzidos com os catalisadores sulfônicos e a resina comercial pode ser atribuída a estrutura de a resina ser mais porosa facilitando o acesso à mistura reacional.

\section{Agradecimentos}

As autoras agradecem ao $\mathrm{CNPq}$, ao $\mathrm{PADCT} / \mathrm{CNPq}$, ao CNPq-PIBIC e à FAPERJ (Bolsa Nota 10 e Bolsa Cientista de Nosso Estado).

\section{Referências Bibliográficas}

1. Coutinho, F. M. B. \& Rezende, S. M. - Polímeros Ciência e Tecnologia, 11, 4, p.222 (2001).

2. Coutinho, F. M. B.; Aponte, M. L.; Barbosa, C. C. R.; Costa, V. G., Lachter; E. R. \& Tabak, D. - Polímeros, Ciência e Tecnologia, 13, 3, p. 146 (2003).

3. Ma, F. \& Hanna, M. - Bio. Tech. 70, p.1 (1999).

4. Lang, X.; Dalai, A. K.; Bakhshi, N. N.; Reaney, M. J. \& Hertz, P. B. - Bio. Tech., 80, p.53 (2000).

5. Gryglewicz, S. - Bio. Tech. 70, p.249 (1999).
6. Shuchardt, U.; Serceli, R. \& Vargas, R. N. - J. Braz. Chem. Soc., 9, 1, p.199 (1998).

7. Chakrabarti, A. \& Sharma, M. M. - React. Polym., 20, p.1, (1993).

8. Morrison, R. T.; Boyd, R. N. - "Organic Chemistry", Allyn and Bacon, Boston (1987).

9. ASTM D I895-69 - "Apparent density, bulk factor and pourability of plastic materials", in: Annual Book of ASTM, Part. 35, Philadelphia (1975).

10. Teixeira, V. G.; Coutinho, F. M. B. \& Gomes, A. S. - Quim. Nova, 24, 6, p.808 (2001).

11. Figueiredo, L.; Ribeiro, F. R. - "Catálise Heterogênea", Fundação Calouste Gulbenkian, Lisboa (1989).

12. Rabelo, D. \& Coutinho, F. M. B. - Eur. Polym. J., 30, 6, p.675 (1994).

13. Rabelo, D., Coutinho, F. M. B., “Polym. Bull.”, 30, p.725 (1993).

14. Nyhus, A. K.; Hagen, S. \& Berge, A. - J. Appl. Polym. Sci., 76, p. 152 (2000).

15. Kunin, R. - "Ion exchange resins", in: Methods of studying ion exchange resins; cap. 15, Robert Krieger Plublishing, New York (1972).

16. Borré, L. B.; Reinert, F.; San Gil, R. A. S. - Evaluation of clays as catalysts for biodiesel production, Proceedings of the XXVI Latin American Chemistry Congress. Brazilian Chemical Society. Salvador, BA, CT-048 (2004).

17. Silverstein, R. M.; Bassler, G. G.; Morrill, T. C. "Spectrometric Identification of Organic Compounds", John Wiley, Singapura (1991).

18. Struck, M. \& Widdecke, H. - Die Angew. Makromol. Chem., 235, p.131 (1996).

Enviado: 22/06/04

Reenviado: 09/02/05

Aprovado: 24/03/05 